\title{
The relationship between obesity and prostate cancer: from genetics to disease treatment and prevention
}

\author{
Giovanni Lughezzani
}

\begin{abstract}
Recent studies demonstrated that obesity is associated with prostate cancer aggressiveness and prognosis. However, the mechanisms underlying this relationship are poorly understood. Tumor microenvironment has been increasingly considered as an important determinant of cancer growth and progression. In the light of this growing evidence, Ribeiro et al., in a BMC Medicine research article, investigated the gene expression profiles of periprostatic adipose tissue of obese patients with and without prostate cancer and compared them to those of lean patients. Their findings provide the first evidence of a differential gene expression in the periprostatic adipose tissue of obese individuals. Differences were also observed when comparing the periprostatic adipose tissue of patients with and without prostate cancer. Differentially expressed genes are related to cell proliferation and immunological responses. Besides suggesting the genetic bases for the observed relationship between obesity and prostate cancer aggressiveness, these findings provide new insights on the important link between local microenvironment and cancer progression.
\end{abstract}

Keywords: Prostate cancer, obesity, adipose tissue, gene expression

\section{Background}

Obesity represents a well-recognized risk factor in several malignancies, such as gastroenteric tract cancers. Conversely, the relationship between prostate cancer and obesity is still a matter of debate. Recent studies showed that obesity is related to higher prostate cancer grade and stage, as well as to worse oncological outcomes [1-4].

Emerging data suggest the importance of the interactions between cells in the microenvironment and tumor cells to determine cancer growth and progression [5]. When focusing on the prostate, periprostatic (PP) adipose tissue represents the first structure outside the organ capsule; its infiltration by tumor cells has a detrimental effect on the prognosis of patients with prostate cancer [6]. To date, only a few studies investigated the interactions between the adipose microenvironment and prostate cancer cells [7-9]. These studies concluded that PP adipose tissue may play an important role by releasing cytokines and growth factors, such as interleukin- 6 and matrix metalloproteinases, that may promote tumor cell proliferation and migration.

Correspondence: lughezzani.giovanni@hsr.it

Department of Urology, Vita-Salute San Raffaele University, Milan, Italy
These interactions may have a key-role in determining prostate cancer aggressiveness and progression.

However, to date, no studies have investigated whether the relationship between prostate cancer and obesity may be attributable to changes in the genetic characteristics of PP adipose tissue of obese individuals. Ribeiro et al. [10] have attempted to answer this question by determining the gene expression profiles of PP adipose tissue of obese individuals and comparing them with those of lean patients with or without prostate cancer.

\section{Obesity and prostate cancer: unraveling the mechanisms behind the association}

While growing evidence suggests an important link between obesity and several human malignancies, the mechanisms underlying this relationship are still poorly understood. In the current study, evaluation of the PP adipose tissue of 18 patients (6 with benign prostatic hyperplasia, 6 with organ-confined prostate cancer and 6 with extra-prostatic prostate cancer) was performed. Tissue samples were collected during surgery. In each group, three patients were lean and three patients were 
obese/overweight. The authors identified several genes differentially expressed in the PP adipose tissue of obese patients (for example, FADS1, LEP and ANGPT1). These genes are mainly related to anti-lipolytic, lipogenic, proliferative and anti-apoptotic activities. Genes linked to the inflammatory response (for example, NPY1R and FADS1), were also differentially expressed in the PP adipose tissue of obese patients, thus determining a favorable environment for disease progression.

Similarly, the authors showed that several genes involved in cell cycle and proliferation, as well as those involved in adipocytes differentiation (for example, PLCB1 and FFAR2) were differentially expressed in the PP adipose tissue of prostate cancer patients, determining an increase in its thickness. These findings are particularly interesting in light of a recent study that showed a relationship between PP adipose tissue thickness and prostate cancer aggressiveness [11]. In addition, up-regulation of genes that reduce immunosurveillance, which may favor prostate cancer progression, was also observed.

Taken together, these findings provide new insights into the importance of PP adipose tissue in creating a favorable environment for prostate cancer cells proliferation and disease progression.

To date, only a few studies have examined the link between PP adipose tissue and prostate cancer. Finley et al. observed an increase in interleukin-6 (IL-6) in the PP adipose tissue of prostate cancer patients relative to individuals without prostate cancer [7]. In addition, IL-6 levels correlated with tumor grade [7]. Similarly, Ribeiro et al. showed that the PP adipose tissue may modulate prostate cancer cells' growth and migration through a local increased activity of matrix metalloproteinase (MMP) [8]. Finally, Sacca et al. confirmed these observations by demonstrating an increased secretion of proMMP-9 by the PP adipose tissue of patients with PCa [9]. These findings confirmed the fundamental role of local microenvironment in determining cancer cells proliferation and migration.

However, the mechanisms regulating the secretion of cytokines and growth factors by PP adipose tissue are still largely unknown. In the current study, several genes differentially expressed both by the PP adipose tissue of obese patients and by the PP adipose tissue of prostate cancer patients were identified, suggesting that pathways involved in cell growth and proliferation, as well as in immunological responses, may be altered in these individuals. Based on their findings, the authors hypothesize a "cross-talk" mechanism between PP adipose tissue and cancer cells that may ultimately result in more aggressive prostate cancer and promote disease progression, especially in obese patients.

While this hypothesis should be interpreted with caution due to the small number of patients included in the current preliminary study, these findings provide important evidence regarding the key role of the adipose microenvironment in determining prostate cancer aggressiveness and tumor progression, and shed light on the genetic pathways that may be involved in the complex relationship between obesity and prostate cancer.

\section{Future directions and conclusions}

The differential expression of several genes represents the key for identifying pathways involved with cancer cell proliferation and tumor progression. In this light, the importance of the current study is at least two-fold. First, Ribeiro et al. demonstrated a different gene expression in obese patients relative to lean patients, irrespective of the presence of prostate cancer. By showing an up-regulation of genes related to lypolitic, lipogenic, proliferative and antiapoptotic activities in obese patients, this study provides the first genetic explanations for the observed relationship between obesity and prostate cancer aggressiveness. Second, the authors demonstrated different gene signatures in the PP adipose tissue of prostate cancer patients, suggesting the presence of a "cross-talk" mechanism between tumor cells and adipose tissue cells to create a favorable environment to prostate cancer progression.

These findings should promote future studies to further investigate the relationship between local microenvironment and cancer cell growth. The genetic pathways that were identified in the current study may represent potential objectives for targeted therapies. In addition, gene expression profiles may also be used to better stratify the prognosis of patients with prostate cancer. Finally, the better understanding of the PP adipose tissue biology may further promote the development of chemo-preventive strategies and lifestyle measures meant to reduce the number of life-threatening prostate cancers.

\section{Abbreviations}

IL-: interleukin 6; MMP: matrix metalloproteinase; PP: periprostatic

\section{Acknowledgements}

None

\section{Authors' information}

GL completed a post-doctoral fellowship in urologic oncology at the Cancer Prognostics Health Outcomes Unit in Montreal. He currently works at the Department of Urology of Vita-Salute San Raffaele University in Milan. His research interests focus mainly on prostate, kidney and urothelial carcinoma.

\section{Competing interests}

The author declares that they have no competing interests.

Received: 10 August 2012 Accepted: 25 September 2012 Published: 25 September 2012

\section{References}

1. Calle EE, Rodriguez C, Walker-Thurmond K, Thun MJ: Overweight, obesity, and mortality from cancer in a prospectively studied cohort of U.S. adults. N Engl J Med 2003, 348:1625-1638. 
2. Amling CL, Riffenburgh RH, Sun L, Moul JW, Lance RS, Kusuda L, Sexton WJ, Soderdahl DW, Donahue TF, Foley JP, Chung AK, McLeod DG: Pathologic variables and recurrence rates as related to obesity and race in men with prostate cancer undergoing radical prostatectomy. J Clin Oncol 2004, 22:439-445.

3. Maclnnis RJ, English DR: Body size and composition and prostate cancer risk: systematic review and meta-regression analysis. Cancer Causes Control 2006, 17:989-1003.

4. Capitanio U, Suardi N, Briganti A, Gallina A, Abdollah F, Lughezzani G, Salonia A, Freschi M, Montorsi F: Influence of obesity on tumour volume in patients with prostate cancer. BJU Int 2012, 109:678-684.

5. Valastyan S, Weinberg RA: Tumor metastasis: molecular insights and evolving paradigms. Cell 2011, 147:275-292.

6. Cheng L, Darson MF, Bergstralh EJ, Slezak J, Myers RP, Bostwick DG: Correlation of margin status and extraprostatic extension with progression of prostate carcinoma. Cancer 1999, 86:1775-1782.

7. Finley DS, Calvert VS, Inokuchi J, Lau A, Narula N, Petricoin EF, Zaldivar F, Santos R, Tyson DR, Ornstein DK: Periprostatic adipose tissue as a modulator of prostate cancer aggressiveness. J Urol 2009, 182:1621-1627.

8. Ribeiro R, Monteiro C, Cunha V, Oliveira MJ, Freitas M, Fraga A, Príncipe P, Lobato C, Lobo F, Morais A, Silva V, Sanches-Magalhães J, Oliveira J, Pina F, Mota-Pinto A, Lopes C, Medeiros R: Human periprostatic adipose tissue promotes prostate cancer aggressiveness in vitro. J Exp Clin Cancer Res 2012, 31:32.

9. Sacca PA, Creydt VP, Choi H, Mazza ON, Fletcher SJ, Vallone VB, Scorticati C, Chasseing NA, Calvo JC: Human periprostatic adipose tissue: its influence on prostate cancer cells. Cell Physiol Biochem 2012, 30:113-122.

10. Ribeiro R, Monteiro C, Catalán V, Hu P, Cunha V, Rodríguez A, GómezAmbrosi J, Fraga A, Príncipe P, Lobato C, Lobo F, Morais A, Silva V, SanchesMagalhães J, Oliveira J, Pina F, Lopes C, Medeiros R, Fruhbeck G: Obesity and prostate cancer: gene expression signature of human periprostatic adipose tissue. BMC Med 2012, 10:108.

11. van Roermund JG, Hinnen KA, Tolman CJ, Bol GH, Witjes JA, Bosch JL, Kiemeney LA, van Vulpen M: Periprostatic fat correlates with tumour aggressiveness in prostate cancer patients. BJU Int 2011, 107:1775-1779.

\section{Pre-publication history}

The pre-publication history for this paper can be accessed here: http://www.biomedcentral.com/1741-7015/10/109/prepub

doi:10.1186/1741-7015-10-109

Cite this article as: Lughezzani: The relationship between obesity and prostate cancer: from genetics to disease treatment and prevention. BMC Medicine 2012 10:109.

\section{Submit your next manuscript to BioMed Central and take full advantage of:}

- Convenient online submission

- Thorough peer review

- No space constraints or color figure charges

- Immediate publication on acceptance

- Inclusion in PubMed, CAS, Scopus and Google Scholar

- Research which is freely available for redistribution

Submit your manuscript at www.biomedcentral.com/submit
Biomed Central 